\title{
Locating Difference With Teacher Candidates
}

\author{
Lee Anne Block
}

University of Winnipeg

\begin{abstract}
How to teach about difference is critical to education. This paper discusses teaching about difference in locations or contexts where the majority of teacher candidates were of the dominant culture. As a teacher educator, I have worked with teacher candidates on becoming aware of the relationships between their subject positions and the subject positions of others. The exploration of those relationships was contextualized by the different physical locations and teaching and learning environments, within which privilege, dominance, and marginalization were constructed and experienced in specific forms. This paper relates my emerging pedagogy for teaching about difference, as well as describing some teacher candidates' perspectives on learning about difference. It reflects on my experiences teaching courses in multiculturalism and social justice in two specific locations: the teaching and learning department of a small American university in North Dakota and an education faculty in Manitoba. For teacher candidates positioned within dominant culture, difference can be uncomfortable. Teaching about difference meaningfully and navigating this discomfort is central to teacher education oriented to equity.
\end{abstract}

Keywords: Teacher education; difference; equity 


\section{Locating Difference With Teacher Candidates}

As a teacher educator focused on how difference is experienced and understood in educational contexts, I have worked with teacher candidates on becoming aware of the relationships between their subject positions and the subject positions of others. The exploration of these relationships was contextualized by the different physical locations and teaching and learning environments, within which privilege, dominance, and marginalization were constructed and experienced in specific forms. In this paper, I convey my emerging pedagogy for teaching about difference, and I describe some teacher candidates' perspectives on learning about difference. This paper reflects my experiences teaching courses in multiculturalism and social justice in two specific locations: the teaching and learning department of a small American university in North Dakota and an education faculty in Manitoba. In both settings, the majority of teacher candidates were of the dominant culture. For these teacher candidates to become good teachers of Aboriginal students and of all students, teacher education must be oriented to teaching about difference in meaningful ways.

Teacher candidates enter faculties of education from varied subject positions (Staunaes, 2003; Feiman-Nemser, 2001). They develop their professional identities through actions contained by the institutional structures they must function within (Block \& Betts, in press). However, the majority of teacher candidates in most Canadian and American faculties of education are of the dominant culture (Manitoba Education \& Citizenship and Youth, 2006; Ladson-Billings, 2005). Their varied personal experiences are rooted in a shared dominant perspective (Tupper, 2011). This common perspective can become a barrier to teaching and learning as it can and does restrict teacher candidates from understanding differences, such as Aboriginal cultures or such as living in poverty, as other than a deficit (Cummins, 2003), or an aberration from the norm. This narrow perspective limits teacher candidates' awareness of their students' experiences.

In 2007, the Manitoba Ministry of Education required courses in multiculturalism, special education, and Aboriginal education in order to broaden teacher candidates' perspectives. These courses address a variety of differences. This paper considers teaching about differences, illustrated through specific teaching and learning contexts. It distinguishes between learning about difference and integrating that learning into practice. Memon (2013) has identified this as the distinction between teaching about diverse perspectives and teaching from diverse approaches. For example, learning about Aboriginal cultures, although important, is not synonymous with integrating Aboriginal perspectives into one's teaching. Similarly, information about Muslim traditions is a necessary but not sufficient condition for intercultural understanding. An approach based on knowledge transmission is insufficient for teaching and learning as a complex process of making meaning (Davis, Sumara, \& Luce-Kapler, 2008). If making meaning is collaborative, different cultural perspectives must be integrated (Block, 2012). When making meaning is tied to equity in education, then pedagogies for teaching about difference with teacher candidates of dominant culture need to be developed and applied as argued in the works of Adams, Bell, and Griffin (1997), Ellsworth (1997), Haberman (1996), and Ryan, Pollock, and Antonelli (2009). 
Purposeful teaching, as I try to practise it, involves shared meaning making and shared purpose. That purpose may include objectives or outcomes, but will also be connected to values and beliefs. Although I generate the purpose, it is contextualized in an interactive curriculum where students' (teacher candidates) purposes are integrated. My teaching purpose may guide experiences in the course but will not determine them because within an interactive curriculum, purpose is shaped by what students know or do not know and by their subjectivities. My teaching purpose has been to construct a milieu or context where teacher candidates question their assumptions and those of the dominant culture and develop multiple perspectives and a social justice agenda. Questioning my own assumptions (Newman, 1987) has been part of this process. What assumptions have I made about my students and how do these assumptions get in the way of purposeful and meaningful pedagogy? The experiences in the two teacher education settings I describe in this paper encompass the limitations of my teaching position as well as its strengths.

In both settings, the classes were approximately 30 students with the great majority being female. Teacher candidates' texts from both settings have been the source for my analysis of their understanding of difference in educational contexts. These texts include individual and group assignments, in-class responses, and peer critiques. Texts were made available with permission from the students. Direct quotations from those texts are either anonymous or identified with a pseudonym. My experiences with the teacher candidates in class and in conversation have framed my perspective.

One approach I have drawn on in teaching about difference has been to employ a pedagogy of discomfort (Boler \& Zembylas, 2003). A pedagogy of discomfort assumes the presence and hegemony of a dominant culture. Dominance is constructed and maintained, in part, through marginalization, repression, or segregation of others. Dominant culture establishes norms, which mark difference as negative, as deficit (Cummins, 2003; Dei, 1999). A pedagogy of discomfort requires unpacking the process by which schooling participates in hegemony, including schooling's role in maintaining dominant culture (Britzman 1999; Luke, 2008). A pedagogy of discomfort integrates an additional dimension to teaching about difference because it takes into account the emotional investment individuals have in dominant culture, both those embedded in it and those on the margins.

In examining their relative privilege, teacher candidates experience the discomfort of questioning the assumptions and values that give them comfort, that weave the fabric of their everyday experiences, and that frame their hopes. Confronting the power structures that name difference and their participation in that process is uncomfortable. This pedagogy is purposeful and it would not be adopted in all teaching and learning contexts. It is directed to locations where the teacher candidates participate in the privilege of the dominant culture within which they are embedded (Sleeter, 1995). Privileged teacher candidates are not a homogeneous group and their privilege is relative (Razack, 1998). However, from within a privileged position, it is difficult to critique what appears to be working well in one’s daily life (Milner, 2007). 


\section{Locating Multiculturalism}

The first course I taught which had a focus on difference was Multiculturalism, at a small university in North Dakota. Preparing the course, my assumption had been that my passion for equity in education would be shared and that the teaching problem would be to effectively critique the issues raised about multicultural education. After the first weeks of teaching, it was apparent that teacher candidates did not recognize issues in multiculturalism as having much relevance to their teaching lives. Rather, these teacher candidates seemed "to see and produce themselves as unaffected by gender, race or class oppression” (Harper, 1997, p.149). That teacher candidates were uneasy discussing issues related to differences in culture, race, class or sexuality was made explicit in their writing and was implicit in their conduct in class. In this paper, teacher candidates' texts demonstrate their understanding of their teaching identities and of difference. They reveal that teacher candidates' identification with the dominant culture was ingrained. Teaching against that grain (Simon, 1992), questioning dominant culture, was politely resisted.

The course was structured to have teacher candidates explore their personal and professional identities as preparation for understanding different cultural identities. An early assignment asked teacher candidates to describe how their family of origin's values fit with their experience of schooling. They were asked to develop a narrative of a particular story or event, which either demonstrated a conflict between home and school or illustrated the coherence of home and school. As I read their papers, I found that teacher candidates almost uniformly reported on the congruency of school and family. It seemed there had been only limited conflicts between family and school. One teacher candidate wrote, "I cannot think of one instance in my schooling where I remember there being a discrepancy between my family's values and the ideas that my school believed” (Gemma, reflection, January, 2007). This was echoed in many of the papers. If family and school cultures are experienced as comfortably congruent, a layered or oppositional identity is not readily available.

In another assignment, teacher candidates developed a family cultural history, which included interviewing a family member. In the following excerpt from a family history, one teacher candidate describes his family values as foundational to his teaching identity:

What does all this mean to me in becoming a teacher? My parents instilled a hard work ethic into me. There is no chance a person can become an effective teacher without putting the time into his or her work. Slacking just does not cut it in the teaching world. My parents also instilled punctuality into me. While this is important for any job, in teaching brings a whole new meaning. For example, if a teacher is late in getting to his class and a fight breaks out when that teacher is not there, it could very well be one’s job. (Stan, Family Cultural History, January, 2007)

This excerpt reveals this teacher candidate's concern with his respectability. He values working hard and being punctual in keeping his future position. He sees the need to be present to deal with a fight in the classroom, but expresses no concern about the potential 
for fights breaking out; rather he assumes this to be part of the school landscape. He perceives institutional school values and family values as synchronous.

The extract below, from a different teacher candidate, also describes the congruency of her family and her school. In addition, it demonstrates that the teacher candidate understands how family cultures can differ and that not all families are as congruent with school culture as her own are. What she does not consider is how those differences can lead to conflict. The absence of conflict was thematic in teacher candidate writing. Even where differences are acknowledged, there is an assumption that they can be shared or celebrated without the process of acknowledging differences of power, status, or historical experience.

I truly appreciate that much of the time my home and school cultures lined up with one another. However, I realize that this is not the case for all students. I believe that realizing how important my family culture is to me will help me to remember that each of my students will have their own unique family culture as well. It is my goal to get to know each of my students and to learn about the things that are important to them. Making my classroom a place where they are able to share about their families and traditions will help me to accomplish this goal. (Lucy, Family Cultural History, January, 2007)

As I read the family cultural histories, I was surprised at the extent to which American mainstream values were present and unchallenged throughout the teacher candidate texts. Liberal individualism was the prevalent value system expressed. Analysis of the texts demonstrated their belief that success is produced by an individual's hard work. Social or economic factors in success were not addressed. Throughout the texts responsibility, hard work and punctuality were emphasized as values families shared with schools. Teacher candidate texts affirmed that applying these values to schooling would lead to success. Reported conflicts, in families and between families and the schools, were rare and limited to parents having higher standards than the school.

In purposeful teacher education, neo liberal discourses need to be examined and disrupted (Sanford, Williams, Hopper, \& McGregor, 2012). Teacher candidates are not required to adopt alternate perspectives, but can be required to scrutinize dominant discourses. In North Dakota, the teacher candidates persistently defined success (and failure) in school as a product of individual effort and not of social categories such as gender, sexuality, class, or race, even when those categories were identified in my discourse and in their text, Sonia Nieto's (2004), Affirming Diversity: The Sociopolitical Context of Multicultural Education. As I read their assignments, my teaching purpose evolved into linking the social political context to schooling through cultural differences. I assigned a short response paper on Nieto's discussion of how self-concept can be supported by schools that value diverse cultural knowledge. This response was to include any two of the case studies from the text as examples. The teacher candidates' responses, written halfway through the term, acknowledge that there are social differences that negatively affect self-concept. However, teacher candidate texts reiterated that overcoming these difficulties is accomplished through individual will power and hard work. They did not reflect a multicultural orientation to differences in power or a need for social change. 
The teacher candidates acknowledged that differences exist but did not appear to perceive those differences as producing inequity in schools. Teacher candidates identified with the students in the case studies who were "working for the better life of achieving the American dream” (Bert, personal communication, March, 2007). Some suggested that the negative social messages can have a positive effect, acting as an incentive: "Even though Rich (an African -American secondary student in the case study) is affected by the negative message, he has also risen above it by focusing on school and working hard to succeed. In Rich's case, the negative message has been a motivation to prove that he can be successful” (Brenda, personal communication, March, 2007). Success in school is achieved through individual effort or sometimes with the support of an individual caring teacher who teaches respect for all. From one student's perspective, respect is based on understanding that everyone is "the same under the skin" and therefore "teachers need to start teaching their students while they are still young that everyone is the same on the inside. Even though someone may look different they are still all the same” (Noreen, personal communication, February, 2007). Noreen and other teacher candidates' desire to treat all children as equals made disregarding their differences "virtuous" rather than convenient. Denying the children's cultural experiences reproduces dominant culture, reducing equity.

I suggest that these teacher candidates had a strong resistance to seeing themselves as dominant or privileged in relation to others because this would involve making the link between privilege and lack of privilege. Believing that all their students had equal opportunity to succeed in school was important to them. Seeing everyone as the same, the colorblind approach (Lee, Mankart, \& Okazawa-Rey, 2002), was more comfortable than having to take cultural, social, or economic differences into account. My teaching purpose was to find ways to probe or unpack those differences with them (Tupper, 2011).

During the work on personal and professional identities, teacher candidates found it difficult to name their own conflicts. As the course took up social identities, social conflicts were also difficult for teacher candidates to name. What was not said in response to For Angela (MacDonald \& Prouty, 1995), a film we studied, affirmed that teacher candidates did not want to consider conflict based on race. The Canadian drama depicts a factual incident of White high school students directing racist language and behavior to an Aboriginal woman and her young daughter. The DVD version includes an interview with the actual woman, Ruth Gordon, and her now teenage daughter. In introducing the film, I had described it as depicting a racist incident. I added that I had shown the film to other classes and that some found it difficult to watch the racist behavior and hear the language.

A brief written response to the film was assigned, asking teacher candidates to describe the relationship between mother and daughter and to discuss "how the school gets involved in dealing with the situation." In the responses, only one teacher candidate out of 26 used the words racism or racist, despite my use of the term and the use of the term in the discussion segment of the DVD. It was a piece about racism, how it affects families, schools, and perpetrators as well as victims, yet none of the teacher candidates named what occurred as a racist incident, nor did they discuss the mother's and daughter's experience as an experience of racism. An example of teacher candidate 
response is, "The school allows Angela and her mother to go into the classroom to pick out the boy who was saying stuff to them [emphasis added]. The administrator gets involved and made the boy apologize and let them know how much they hurt Angela and her mother" (teacher candidate response, March, 2007). Aside from not using the term racist, this particular response reduces Rhonda's agency and transfers the power to act to the White male principal.

Despite the teacher candidates' inability to name racism, the discussion of schools as sites of racism and the exploration of the American Indian experience were continued. The next video the students saw was a documentary on residential schools, The Indian Boarding Schools: Bittersweet Memories (Reagan \& NDHC, 1999). This time the question for the response to the documentary was constructed to contain a critique: "Why would residential schools be described as 'weapons' in the battle to destroy Indian culture?" Over half the students employed the term weapon or terms such as combat, destroy, wipe out, or harm in their answers to this question, suggesting that they perceived that a culture could be destroyed and that an Indian culture had been attacked. Did this language demonstrate a changed perspective among the teacher candidates or did their responses simply indicate their compliancy with the terms I had introduced? The language of student texts provides implications, not proof, of their understanding. Based on the experiences of the course as a whole, I infer that the teacher candidates' responses indicated compliancy with the terms I had introduced as much or more than indicating an understanding of residential schools as an attack on Aboriginal culture.

The teacher candidates' perspectives on other cultures were not comfortable for me; they contradicted my values of how teachers should conduct themselves with students and communities. I found myself frustrated by the teacher candidates' limited experience and entrenchment in mainstream American values. For these teacher candidates, naming difference was embarrassing, even destructive, because difference from the norm was understood as negative. In response to their position, my teaching had to be focused on finding ways to broaden that perspective so teacher candidates could see difference, not as deficit, but as possibility (Lorde, 1984).

The course was designed to construct space for multiple perspectives. It was in the group presentations about issues in multicultural education in the final weeks of the course that these spaces began to materialize. Choosing, researching, and presenting these issues as well as other collaborative assignments counteracted the focus on individualism. The practice of sharing perspectives in group work on the case studies, pair work on the issue presentations, and temporary groupings for discussions were experiences that structured learning as collaborative. To a limited extent, collaborative work can be seen as resistance to dominant culture. Ironically, collaborative work became a valuable strategy for teaching about differences in the Manitoba setting, discussed further in the Locating Social Justice section below.

Developing an analysis of my experience teaching Multiculturalism in an American college in the mid 2000s was critical because the events had challenged my assumptions about teacher candidates and about my teaching. When I took up a similar teaching position five years later in an urban Canadian university, I held different assumptions. I believed there would be a different teaching milieu, based on the distinct 
culture, location, and timeframe. In addition, there was a structural change; the social justice course was not the only required course in the education program for examining difference.

\section{Locating Social Justice}

In the Manitoba setting, teacher candidates' responses and texts evidenced a less homogeneous worldview than that of their American counterparts. However, as in North Dakota, the majority of teacher candidates were of the dominant group. Most were White, female, and middle class. Few of them had had to inspect their own privilege, although most had awareness of "the underprivileged" whom they perceived as separate from themselves, a group requiring social support. When they researched equity issues such as homelessness, poverty, and food security, their papers and presentations were about others who suffered these inequities. Like the American teacher candidates, if their own lives had included deprivation or loss, they rarely disclosed those experiences. How they might be implicated in others' experiences of loss and deprivation was not often present in their texts or presentations.

The social justice course, like the multiculturalism course, was designed so teacher candidates would examine their own positioning and then consider how others position themselves and are positioned. The relationship of different subject positions was explored. Course work required teacher candidates to move from exploring personal experiences of teaching and learning to an understanding of teaching and learning as social experience, which included a consideration of power structures. A major assignment (done in small groups or in pairs) was to research, present, and critique a social justice issue of their choice. Sometimes teacher candidate research on these issues encompassed government or education policy. Considering community action on the issue was incorporated in the individual extension of the assignment, where teacher candidates developed an action plan on the issue in relation to their practicum community or to a community group with which they worked. The group assignment read:

With your partner, choose a social justice (equity) issue (for example, cultural differences in parent/school relations or Afro-centric schools) to research and teach to our class. In choosing your issue, remember you need to be able to provide more than one perspective on the issue.

This focus on perspectives was designed to disrupt the us/them dichotomy of under privileged and privileged, or victim and perpetrator. Requiring multiple perspectives was effective to varying degrees. For example, a presentation on bullying focused on prevention, teacher candidates included the perspectives of perpetrator, victim, and bystander as well as teacher and student. They also explored stereotypes. The presentation left room for confusion about the issue. A presenter reflected that the audience of teacher candidates had difficulty discussing their own experiences as schoolchildren, which reflects the general hesitancy to address personal conflict.

In the multiculturalism course, perspectives had been provided through case studies from Nieto's (2004) textbook. My experience suggested there were limitations in developing perspective using case studies. Thus, in the social justice course, I used a set of readings offering multiple perspectives and no textbook of case studies. Teacher 
candidates were required to research alternative perspectives in their responses to these readings and through research on the social justice issue of their choice. Some researched and developed their own case studies for their classmates to consider during the presentations. Collaborating on the research and presentation in itself required sharing perspectives.

Choice was also a significant element in this assignment although teacher candidate choices had to be approved by the instructor. Choice allowed for a comfort zone for individuals, if needed. For example, the topic of homelessness was chosen every year, apparently more comfortable to discuss because there is social consensus that shelter is a human right. Engaging with issues that belonged, or were seen to belong to others was the predominant choice of topic. When a group of three students presented on the topic of White privilege, it was the first time this topic had been chosen in the three years of teaching the course. The topic had the potential to have students confront their own subject positions and social conflict.

One of the presenters on White privilege wrote in her reflection that the group really struggled with how to present the issue to the class since the majority of the class was White. "The group worried that the class might reject or oppose its perspective on this issue.” (reflection, March, 2013) Rejecting or opposing each other was not part of the culture of our education program, or of many faculties of education where a culture of caring and of niceness (Robertson, 1997) is prevalent. Responses to the presentation on White privilege (see some below) suggest that the teacher candidates were able to connect to the concept of their own privilege, even if many did not make further connections to inequities at that time. My experience has demonstrated that critiquing privilege involves a layered learning experience, one which deepens over time.

The following excerpt is from another teacher candidate's assigned critique of the presentation:

Before the presentation I did not have much prior knowledge on this issue because it has never really been discussed in our university classes or has not been called that but after the presentation and throughout the presentation I realized I really did know what it is. I have experienced White privilege first hand from both sides from a White person's perspective and from a non-White person's perspective. I am [a person of colour] and White so I feel like I have the consequences and privileges of this issue at different times. (critique, March, 2013)

In the paper, the teacher candidate explored her experiences of privilege and discrimination. She had been concerned that her White classmates might have "no idea how it feels to feel the negative side effects of White privilege” (reflection, March, 2013), but found the discussion included different perspectives. Not all students accessed multiple perspectives. For example, one teacher candidate's response indicated she was unable to understand how the White privilege experienced in social settings impacts on student experience in the classroom.

In her reflection, a second presenter focused on the difference between White privilege where "White people benefit without knowing they do" and racism, which is "deliberate." This teacher candidate also stated that teaching effectively about social 
justice issues requires that students or teacher candidates "are able to connect it to themselves” (reflection, March, 2013), as did another teacher candidate who in her critique valued the presenters' ability to connect with the class. The White privilege presentation included the use of white as flesh colour in crayons and bandages as examples. The teaching problem becomes how to connect these social justice issues to teacher candidates' experiences without diluting the differences or the difficulties.

Like the American students, these teacher candidates were often hesitant to voice conflicting views, to disagree with each other or with the instructor. However, they were able to write about the contradictions they experienced. In a reflection on her presentation on human trafficking, a teacher candidate wrote:

I had trouble figuring out the perspective of the trafficker. I found some research discussing issues of control for human traffickers, and problems such as debt, drugs, or gangs that led them to become involved in human trafficking. I wasn't confident in understanding the perspective of the trafficker and therefore I don't think I was able to effectively illustrate their perspective in our presentation. (reflection, March, 2013)

In acknowledging her limitations, the teacher candidate demonstrated her awareness of perspectives beyond her own. She then proceeded to advocate for the construction of linkages between disparate perspectives:

In order to make this presentation more relevant to our class, I felt it was important to show the perspective of the average Canadian citizen. I think we were effective in demonstrating this perspective by openly discussing our original lack of awareness about the issue and feeling that the issue had little impact on us personally. When analyzing my own perspective, I felt that it was necessary to get more information on how the issue might directly impact me and my classmates. I found research on the impacts of human trafficking on Canadians both economically and socially. I think that informing students on the reality of the impact within our own community will widen their perspective and give them greater connection to the issue.

The teacher candidate identified herself as the average Canadian citizen but she also affirms that such a citizen must be connected to issues that are not average, that do not "impact on us personally" (reflection, March 2013date).The us/them dichotomy was interrupted.

\section{Implications}

In developing the social justice course for the urban university, I no longer assumed that teacher candidates would be committed to equity in education. This starting point allowed for an exploration of prior learning and for an examination of all our social positions. To do this effectively, the instructor must be accepting of teacher candidates' different subject positions and experiences. At the same time, the curriculum must introduce and reintroduce the interlocking social positions and the power relations that determine them. This has been and continues to be a difficult balance to establish. 
Building community is a support to generating this balance between accepting and contesting our subject positions (Sanford et al., 2012). Taking the risk of exploring privilege is less problematic if one trusts the people around one. The collaborative structure and process in this course included group discussions of the readings, group responses to the lectures, and the group presentation of a social justice issue. This collaborative process formed a container (Salverson, 1996) to support teacher candidates in risk-taking, as they faced uncertainty. The container cannot be too containing; it must have room for conflicting perspectives. The container must have a gap within which agentic actions can be constructed and implemented. The gap affirms the limitations of any structure. This image of the container is amplified by the concept of "enabling constraints" (Davis et al., 2008, p.193). If teaching and learning is seen as a complex system, that system includes both structure and flexibility. In constructing learning tasks, activities, or problems, we need constraints or rules that are enabling and thus have gaps for new understandings to emerge.

Pedagogically, a collaborative approach integrates the position that teaching for equity involves a movement from the realm of the personal to the social. A student wrote in a reflection: "I think that because our cohort has developed a great sense of community, it was not too difficult for people to share their thoughts" (reflection, March, 2013). In addition to the sense of community within this particular teacher candidate cohort, community had been strengthened because I had taught the cohort in a previous course. The first course had been a social studies methods course, which also focused on equity. Teacher candidates were aware of and fairly secure about my teaching style and expectations. Together, we had shared experience and enthusiasm from the first course. Perhaps that comfort made it easier to critique the limitations of our subject positions, forming a container that included a gap for risk-taking?

As the instructor, I constructed openings for teacher candidates to explore the contradictions between our social positions and those of others. I also participated in and identified those contradictions. I affirmed that working for equity also involves identifying inequities and that discussions of dominant and marginalized groups are part of understanding inequity. These discussions may make those in dominant groups uncomfortable about the social structures that privilege them and punish others (Razack, 1998). I emphasized that as individuals, teacher candidates are not responsible for those social structures although they participate in and enact them from their social positions and need to be aware of that participation. It was important to distinguish the difference between, for example, living with the history of colonization as the descendant of a colonizer and as an Aboriginal person. It was also important to build understanding of our collective responsibility to address inequities. To build that understanding requires that one does not disengage from difficult or troublesome problems (Staunaes, 2003).

How to teach about difference is critical to education and to Aboriginal education. Purposeful teaching involves teaching-in-context. This paper has discussed teaching about difference in two different locations of teacher education. There were other locations where I did this work and I learned from them as well. Teaching purpose and position emerge from context. There are no recipes. Therefore, the summary that follows is meant to present possibilities that can be taken up contextually-with respect to location. 
Naming differences and acknowledging privilege are closely related. Constructing a milieu within which there can be honest acknowledgement of difference is integral. How to construct such a milieu is idiosyncratic, but its construction will involve the instructor working through their own assumptions about teaching and learning, and about equity. Modeling a self-critique supports that same process with teacher candidates. I remember the impact of listening to my professor describe her own success in the academy as having been built on the backs of other women, the women who cared for her children while she studied and worked. Connecting equity issues to teacher candidates' personal experience involves retrieving those experiences, and making room for them. At the same time, those personal experiences need to be seen in relation to other complex social issues. Connecting to student experiences should not dilute equity issues. Similarly, having a choice of which issues to pursue allows teacher candidates' to make connections. However, their choices need some supervision to avoid teacher candidates taking the path of least resistance as they pursue an understanding of equity. Collaboration is a strong tool for countering the neo-liberal version of success. If collaboration is built into course work, multiple perspectives are more accessible. This paper has focused on working with teacher candidates where the majority was of the dominant class and identified as Caucasian or White. Within that positioning, their privilege is relative. In North Dakota, one student identified as American Indian. Within the Manitoba class, as indicated in the texts, there were a few students who did not identify as White. Working with a heterogeneous class would change the context and the pedagogy.

The pedagogical structures I describe can be strengthened by structural changes in institutions of teacher education. Such changes can improve the context for teaching about difference. An example is the important variation between the American and Canadian settings, with the Manitoba setting having more than one required course for examining difference. The Manitoba cohort was taking a required course in Aboriginal education at the same time as the social justice course. Teacher candidates were able to make connections between the critical perspectives of the Aboriginal education and the social justice courses and would refer to concepts and issues from their Aboriginal education course. For example, they brought a sense of outrage about residential schools into our discussion of schools' socializing function. I have argued that collaboration is a strategy to undermine the focus on individualism. The teacher candidates experienced a shared discourse and perspective between me and the professor of Aboriginal Education; our very partial collaboration in a pedagogy of discomfort, which teacher candidates encountered in different locations on the same map.

These structural changes to teacher education must be pursued as part of an orientation to social change. My purpose in teacher education is to make possible a deeper commitment to social change through the discomfort of self-critique and of understanding one's complicity in inequities. A context for examining those inequities and one's complicity in them can be constructed through meaningful collaboration that provides both comfort and difficulty. 


\section{References}

Adams, M., Bell, L.A., \& Griffin, P. (Eds.).(1997). Teaching for diversity and social justice. New York, NY: Routledge.

Block, L.A. (2012). Re-positioning: Internationally educated teachers in Manitoba school communities. Canadian Journal of Education, 35(3), 85-100. Retrieved from http://ojs.vre.upei.ca/index.php/cje-rce/article/view/1080/1325

Block, L.A., \& Betts, P. (in press). Sustaining/containing agency in an alternative teacher education program. Working Conference Papers 2012. Canadian Association for Teacher Educators (CATE).

Boler, M., \& Zembylas, M. (2003). Discomforting truths: The emotional terrain of understanding difference. In P.P. Trifonas (Ed.), Pedagogies of difference: Rethinking education for social change (pp.110-136). New York, NY: RoutledgeFalmer.

Britzman, D. (1999). Practice makes practice: A practical study of learning to teach. Albany, NY: State University of New York Press.

Cummins, J. (2003). Challenging the construction of difference as deficit: Where are identity, intellect, imagination, and power in the new regime of truth? In P.P. Trifonas (Ed.), Pedagogies of difference: Rethinking education for social change (pp. 42-60). New York, NY: RoutledgeFalmer.

Davis, B., Sumara, D., \& Luce-Kapler, R. (2008). Engaging minds: Teaching in complex times. (2nd ed.). New York, NY: Routledge.

Dei, G. (1999). The denial of difference: Reframing anti-racist praxis. In Race, ethnicity and education, 2(1), 7-38. doi: 10.1080/1361332990020109

Ellsworth, E. (1997). Teaching positions: Difference, pedagogy, and the power of address. New York, NY: Teachers College Press.

Feiman-Nemser, S. (2001). From preparation to practice: Designing a continuum to strengthen and sustain teaching. The Teachers College Record, 103(6), 10131055.

Haberman, M. (1996). Selecting and preparing culturally competent teachers for urban schools. In J. P. Sikula (Ed.), Handbook of research in teacher education (2nd ed.), (pp.747-760). New York, NY: McMillan.

Harper, H. (1997). Disturbing identity and desire: Adolescent girls and wild words. In S. Todd (Ed.), Learning desire: Perspectives on pedagogy, culture, and the unsaid (pp.141-159). New York, NY: Routledge.

Ladson-Billings, G. (2005). Culturally relevant teaching. Mahwah, NJ: Lawrence Erlbaum. 
Lee, E., Mankart, D., \& Okazawa-Rey, M. (Eds.). (2002). Beyond heroes and holidays: A practical guide to K-12 antiracist education, multicultural education and staff development. Washington D.C.: Teaching for Change.

Lorde, A. (1984). Sister/Outsider. New York, NY: Crossing Press.

Luke, A. (2008). Race and language as capital in schools. In R. Kubota \& A. Lin (Eds.), Race, culture, and identities in second language education. London, England: Routledge.

MacDonald, J. (Producer), \& Prouty, D. (Writer/Director). (1995). For Angela [Motion Picture] Canada: National Film Board of Canada.

Manitoba Education, \& Citizenship and Youth. (2006). Belonging, learning, growing: Kindergarten to Grade 12 action plan for ethnocultural equity. Retrieved from http://www.edu.gov.mb.ca/k12/docs/reports/equity/belonging_learning_growing.p $\underline{\mathrm{df}}$

Memon, N. (2013). Diverse perspectives in teacher education (pp 358-378). In L. Thomas (Ed.), What is Canadian about teacher education in Canada? Multiple perspectives on Canadian teacher education in the twenty-first century. CATE Working Conference Papers 2011: Canadian Association for Teacher Educators (CATE). Retrieved from https://docs.google.com/file/d/0BwVGDOGBDzJdOVdJYmNFRl9KYm8/edit

Milner, H. R. (2007). Race, narrative inquiry, and self-study in curriculum and teacher education. Education and Urban Society, 39(4), 584-608. doi:10.1177/0013124507301577

Newman, J. (1987). Learning to teach by uncovering our assumptions. Language Arts, 64(7), 727-737. Retrieved from http://www.jstor.org/stable/41961669?origin=JSTOR-pdf

Nieto, S. (2004). Affirming diversity: The sociopolitical context of multicultural education. (4th ed.). Boston, MA: Pearson.

Razack, S. (1998). Looking White people in the eye: Gender, race, and culture in courtrooms and classrooms. Toronto, ON: University of Toronto Press.

Reagan, T., North Dakota Humanities Council [NDHC]. (Producers).(1999) The Indian boarding schools: Bittersweet memories. [VHS Video Documentary]. Bismarck, ND: KAT Video Productions.

Robertson, J.P. (1997). Fantasy's confines: Popular culture and the education of the female primary-school teacher. In S. Todd (Ed.), Learning desire: Perspectives on pedagogy, culture, and the unsaid (pp. 75-96). New York, NY: Routledge.

Ryan, J., Pollock, K., \& Antonelli, F. (2009). Teacher diversity in Canada: Leaky pipelines, bottlenecks, and glass ceilings. Canadian Journal of Education, 32(3), 591-617. 
Salverson, J. (1996). The unimaginable occurrence: Storytelling, popular theatre and an ethic of risk. (Unpublished M.A. Thesis). OISE/UT, Toronto.

Sanford, K., Williams, L., Hopper, T., \& McGregor, C. (2012). Indigenous principles decolonizing teacher education: What we have learned. in education, 18(2), 1834. Retrieved from http://ineducation.ca/ineducation/article/view/61/548

Simon, R. I. (1992). Teaching against the grain: Texts for a pedagogy of possibility. Toronto, ON: OISE Press.

Sleeter, C. E. (1995). Reflections on my use of multicultural and critical pedagogy when students are White. In C.E. Sleeter \& P. McLaren (Eds.), Multicultural education and the politics of difference (pp. 415-437). New York, NY: SUNY Press.

Staunaes, D. (2003). Where have all the subjects gone? Bringing together the concepts of intersectionality and subjectification. NORA. 11(2), 101-110. doi:10.1080/08038740310002950

Tupper, J. (2011). Disrupting ignorance and settler identities: The challenges of preparing beginning teachers for treaty education. in education,17(3), 38-55. Retrieved from http://ineducation.ca/ineducation/article/view/71/415 